ORIGINAL ARTICLE

\title{
Required competencies of occupational physicians: a Delphi survey of UK customers
}

\author{
K N Reetoo, J M Harrington, E B Macdonald
}

Occup Environ Med 2005;62:406-413. doi: 10.1136/oem.2004.017061

See end of article for authors' affiliations

Correspondence to:

Dr E B Macdonald, Head of Healthy Working Lives Research Group, Public Health and Health Policy Section, Division of Community Based

Sciences, University of

Glasgow, 1 Lilybank

Gardens, Glasgow G12

8RZ, UK; E.B.Macdonald@ udcf.gla.ac.uk

Accepted 11 January 2005

\begin{abstract}
Background: Occupational physicians can contribute to good management in healthy enterprises. The requirement to take into account the needs of the customers when planning occupational health services is well established.

Aims: To establish the priorities of UK employers, employees, and their representatives regarding the competencies they require from occupational physicians; to explore the reasons for variations of the priorities in different groups; and to make recommendations for occupational medicine training curricula in consideration of these findings.

Methods: This study involved a Delphi survey of employers and employees from public and private organisations of varying business sizes, and health and safety specialists as well as trade union representatives throughout the UK. It was conducted in two rounds by a combination of computer assisted telephone interview (CATI) and postal survey techniques, using a questionnaire based on the list of competencies described by UK and European medical training bodies.

Results: There was broad consensus about the required competencies of occupational physicians among the respondent subgroups. All the competencies in which occupational physicians are trained were considered important by the customers. In the order of decreasing importance, the competencies were: Law and Ethics, Occupational Hazards, Disability and Fitness for Work, Communication, Environmental Exposures, Research Methods, Health Promotion, and Management.

Conclusion: The priorities of customers differed from previously published occupational physicians' priorities. Existing training programmes for occupational physicians should be regularly reviewed and where necessary, modified to ensure that the emphasis of training meets customer requirements.
\end{abstract}

G ood management of the health of workpeople and workplaces requires the advice of competent occupational health $(\mathrm{OH})$ professionals. For those organisations involved in the training of occupational physicians (OPs), there is a need to ensure that training programmes deliver the knowledge, skills, and competencies needed to create a cadre of appropriately skilled doctors to aid good management in healthy enterprises for the 21 st century.

A full list of competencies which may be required of the OPs by the enterprise and its health and safety committee can be derived from the UK Faculty of Occupational Medicine (FOM); World Health Organisation and International Labour Office conventions, recommendations, and resolutions; European Union (EU) directives; the International Commission on Occupational Health (ICOH); and recommendations of the 1997 Glasgow Conference on Core Competencies. ${ }^{1-6}$ These identified eight areas of specific occupational medical knowledge an OP should be competent in, which are summarised under the following headings:

- Hazards: identification and assessment of occupational hazards to health

- Fitness: assessment of disability and fitness for work

- Communication: communication with patients, managers, and other healthcare professionals

- Exposures: advising on impact of environmental exposures

- Promotion: promotion of general health in the workplace

- Research: using research methods

- Management: managing an occupational health service

- Law: advising on $\mathrm{OH}$ law and ethics.

The curriculum for the training of OPs was developed in the UK and elsewhere, and is long established. It is still largely academics who define the skills of the OPs who will be employed by industry. The requirement to take into account the needs of the customer when planning $\mathrm{OH}$ services is well accepted, ${ }^{7-10}$ but this has not been formally evaluated in defining competencies of OPs. This research used a modified Delphi technique to survey UK employers, employees, and health and safety specialists to establish their priorities regarding the competencies they require from OPs. This study aimed to identify any differences in the priorities of respondent subgroups and explore the reasons for those differences. This study also aimed to compare any differences in the previously established priorities of $\mathrm{OPs}^{11}$ to those of their customers and to make appropriate recommendations for occupational medicine training curricula.

\section{METHODS}

Private companies and public sector organisations were recruited from business directories, public sector databases, and from the EEF-The Manufacturers' Organisation (EEF) directory. Proportional sampling was used to recruit organisations within size and geographical subgroups. Employer representatives, usually the director of human resources, or a member of the senior management, were approached for an interview and were also requested to nominate an employee representative or a health and safety specialist to participate

Abbreviations: ANOVA, analysis of variance; CATI, computer assisted telephone interview; EEF, EEF-The Manufacturers' Organisation; EU, European Union; FOM, Faculty of Occupational Medicine; $\mathrm{ICOH}$, International Commission on Occupational Health; $\mathrm{OH}$, occupational health; OP, occupational physician; SIC, Standard Industry Classification; SOM, Society of Occupational Medicine; SPSS, Statistical Package for Social Scientists; TUC, Trade Union Congress; WHO, World Health Organisation 


\section{Main messages}

- All the established competency areas of occupational physicians were regarded as important by their potential customers.

- The three most importance areas of competency for customers of occupational physicians were Law, Hazards, and Fitness.

- There are substantial differences in the rating and ranking of the relative importance of these competencies between the physicians and their customers.

- The subtle differences on the level of importance of the competencies between subgroups were representative of issues central to the subgroups.

- This study points to a need for a change in the emphasis of occupational physicians' training so that it is more aligned to the needs of their customers.

in the study. Trade union workplace safety representatives and health and safety specialists were approached to take part in the survey through the Trade Union Congress (TUC) database.

A modified Delphi technique was used to interview participants in this study. The Delphi technique is a group process using written responses to a series of questionnaires to try to achieve "consensus". ${ }^{12}$ It allows canvassing of opinion of individuals whom it would be difficult to bring together physically. It has been successfully used in health services research ${ }^{13}$ and to collate the opinion of OPs in the past. ${ }^{11}{ }^{14-17}$ In this study a questionnaire was developed and administered to participants, modified, and the modified version re-circulated to participants.

A very poor response was observed ( $1 \%$ ) when piloting the study using postal questionnaires. Therefore, computer assisted telephone interview (CATI) making use of the computer software Ci3 V2.5 (Sawtooth Software Inc., USA), was employed to interview the participants. An optional postal questionnaire was also sent to participants unable to complete a questionnaire by CATI. The questionnaire consisted of both closed and open ended questions and was carefully drafted to minimise technical or medical language.

In the first round interview, respondents were given descriptions of each of the eight training areas described above and asked if the particular area was considered relevant to their company. If so, they were asked further questions which assessed the importance (on a scale of increasing importance from 1 to 5) they attributed to a list of competencies within the training area. They were also asked to describe any other competencies not listed which they felt were important.

All data entered via the CATI software was transferred to the Statistical Package for Social Scientists (SPSS V10; SPSS Inc., USA) for quantitative analysis. The mean rating scores for the questions within each training area were computed by SPSS. Only complete responses from participants who answered all questions within a particular training area were used for the calculation of the mean scores for each training area.

Responses were subgrouped by:

- Company size: small (less than 50 employees), medium (between 50 and 250 employees), and large (more than 250 employees)

\section{Policy implications}

- There should be a review of the occupational medicine training programmes to ensure that occupational physicians are fully competent in the areas which their customers think are important.

- Given the evolution of occupational health there should be regular and systematic evaluation of teaching curricula, taking into account the views of the customers.

- The role, responsibilities, and ethical obligations of occupational physicians should be more widely communicated to their customers.

- Company sector: private (EEF companies or other private companies) or public (Local Authorities, Police Authorities, Health Authorities, and Fire Authorities)

- Industry using Standard Industrial Classification (SIC) ${ }^{18}$

- Respondent representative: employer representative, employee representative, health and safety specialist representative, and trade union representative.

A one way ANOVA test was used to indicate whether there were any significant differences in the mean scores between the respondent subgroups and the Bonferroni pair-wise multiple comparisons helped to determine which means differed. The mean differences were considered significant at the 0.05 level.

Qualitative data analysis was performed by hand, looking at emerging themes in the responses.

In the second round of the study, respondents were asked to rank OPs' competencies in the order of most important to least important. Quantitative as well as qualitative responses from the first round of the study were used to inform the questionnaire used in the second round. In certain topic areas the wording of some of the qualitative responses from round 1 was included in round 2 in order to establish their relative importance. The questionnaires were piloted and a poor response was obtained for postal questionnaires. Piloting of the ranking of the round 2 questionnaires by CATI showed that respondents experienced difficulties in ranking more than three items at a time. The questionnaire was then redrafted to facilitate participation. Responses to the second round questionnaire were analysed by computing the mean ranks for each competency within the eight training areas.

\section{RESULTS}

\section{Breakdown of responses}

In the first round of the Delphi, 1758 employers, employees, and health and safety specialists were approached for an interview by CATI. However, telephone or address problems were encountered in 89 cases and therefore these were excluded from the study analysis. A total of 249 individuals contacted refused to participate in the study and of the remaining 1420 potential contributors, 576 agreed to participate in the study, making the participation rate $35 \%$. Furthermore, 800 trade union workplace safety advisors were also approached through the Trade Union Congress by a postal questionnaire; 185 responses were returned, making the response rate $23 \%$.

Of the 761 interviews in round 1, 13 questionnaires were incomplete and 4 questionnaires were completed by OPs, whose views may be a potential source of bias in the study. These responses were excluded from the study analysis. 


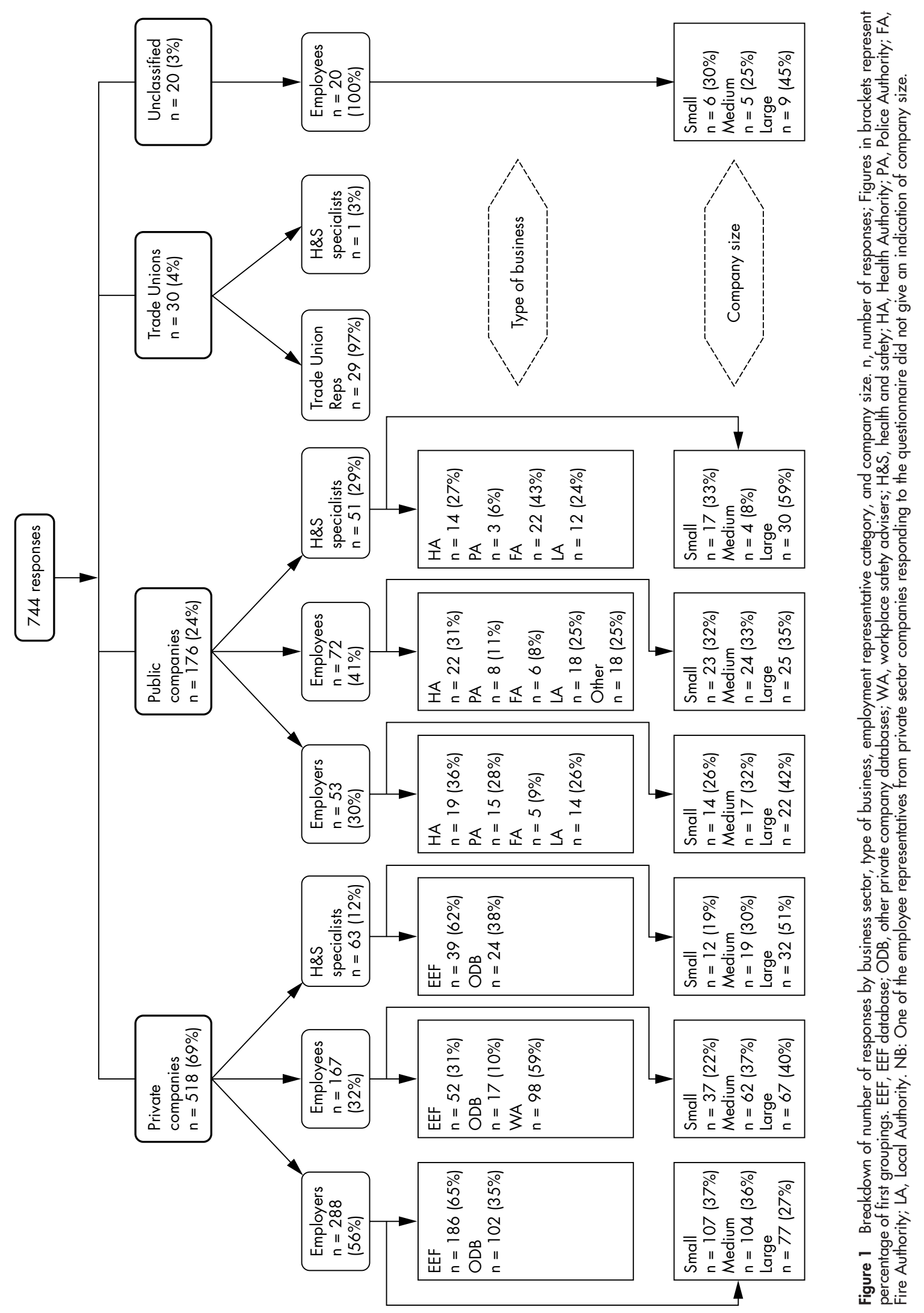

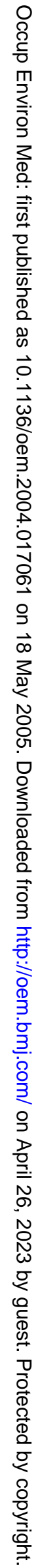


Therefore in total 744 interviews were analysed in the first round and $60 \%$ of these were completed by CATI.

The highest participation rates observed were in the public sector companies (109/174; 63\%). Of the 630 private companies approached from the EEF database, 277 companies responded to a questionnaire $(44 \%)$. However, using other private business databases a $16 \%$ response rate was observed (133/846). Of the 800 Trade Union workplace safety advisers contacted, 185 (23\%) responded to the study and 30 $(28 \%)$ of the 108 trade union representatives contacted participated in the study. When private companies were categorised by size, the large companies had the highest response rate of $38 \%$ (135/357), followed by medium sized companies (34\%; 148/437) and small companies (20\%; 137/ 682 ). When analysed by geographical representation, the majority of companies participating in the study were from England and therefore statistical data analysis by geographical representation was not performed.

Eighty nine per cent of the respondents provided information about their company industry sector. Respondents were subgrouped using the SIC codes, ${ }^{18}$ and it was observed that $31 \%$ of the respondents were from the manufacturing sector, $28 \%$ were from the public service sector, $17 \%$ were from the trade sector, and $13 \%$ were from the building sector. Responses were also subgrouped by respondent representative category as mentioned above. In round l, only 69 employees from the private sector and five from the public sector were referred to the project by employers. Responses from 185 trade union workplace safety representatives were counted as employee responses. Only one of the responses obtained from the trade unions was from a health and safety specialist, the other 29 were from trade union representatives. Responses from safety engineers, safety managers, $\mathrm{OH}$ nurses, and others possessing basic $\mathrm{OH}$ and safety qualifications were classified as health and safety specialist responses. Figure 1 shows the participant breakdown for round 1 .

The same group of contacts as in round 1 were approached in the second round of the Delphi study, and 1230 participants were successfully contacted by CATI. A total of 652 interviews were completed, of which $67 \%$ were carried out using CATI. Thus, the overall response rate in round 2 was $53 \%$. A breakdown similar to the one described for round l was carried out for round 2 participants (not shown).

\section{Round 1 Delphi rating of competencies}

All the established competency areas of OPs were regarded as important by their customers. When participants were asked if training in a particular area was important to their business, the area of Communication was considered important by the majority of the participants. This area was followed by training in the area of Fitness, with Law, Hazards, and Health Promotion pursuing closely behind (table 1). When the participants were asked to rate the required competencies of OPs in order of decreasing importance, the results were as follows: Law, Hazards, Fitness, Communication, Exposures, Research, Promotion, and Management (table 1).

Table 2 indicates the mean scores for the individual competencies within each of the training areas scored by all participants in order of decreasing importance. In the area of Law, for example, it was significantly more important for the physicians to have knowledge of the law than to evaluate compliance or advise employers and employees on their legal obligations.

When responses were subgrouped as described above and analysed there was broad consensus about the required competencies of OPs among the different subgroups of the study population (table 3 ).

The main significant differences $(p<0.05)$ as observed by the one way ANOVA and Bonferroni tests (not shown) were:

- Public sector companies rated training in Fitness higher than private sector companies

- Employees rated training in areas such as Hazards, Exposures, Research, and Promotion higher than employers

- Employees rated training in areas such as Hazards and Promotion higher than health and safety specialists

- Police authorities considered training in Hazards and Communication more important than local authorities

- Fire authorities rated training in Exposures less important than did the health or police authorities

- Trade union representatives rated training in Communication and Research higher than employer representatives.

\section{Round 2 Delphi ranking of competencies}

Table 4 summarises mean scores of the individual competencies scored within each training area by all respondents and by the various subgroups analysed in round 2 . The mean score gives a measure of opinion, with the lowest scores indicating highest priority. When items within a section have similar scores, this indicates that they were considered of the same priority. In the Communication area for example, "reading, writing and speaking clearly" was perceived to be of greater importance than "applying law and ethics for confidentiality" or "communicating with other health and safety professionals". The latter two competencies were considered to be of almost equal importance. All of the subgroups appear to agree on the ranking of the competencies within the training categories of Fitness, Exposures, and Management. The highest variation appears to be in the area of Hazards.

\section{Additional information from Delphi}

Respondents were asked if there were any additional competencies they would expect from an OP. No additional competencies were suggested in any of the eight training

\begin{tabular}{llll|}
\hline \multicolumn{3}{l}{ Table 1} & Results of the mean scores of subject areas indicated for all participants \\
\hline Training area & $\begin{array}{l}\text { \% of respondents considering } \\
\text { training area important }\end{array}$ & $\begin{array}{l}\text { Mean score rating by all } \\
\text { respondents }\end{array}$ & $\begin{array}{l}\text { Importance rating } \\
\text { order }\end{array}$ \\
\hline Communication & 99 & 4.03 & 4 \\
Fitness & 97 & 4.09 & 3 \\
Law & 92 & 4.21 & 1 \\
Hazards & 92 & 4.09 & 2 \\
Promotion & 92 & 3.76 & 5 \\
Exposures & 81 & 3.98 & 6 \\
Research & 75 & 3.88 & 8 \\
Management & 57 & 3.75 & \\
\hline
\end{tabular}


Table 2 Mean scores for individual competencies within each training category

\begin{tabular}{|c|c|c|}
\hline Training area & Competency & Mean scores \\
\hline \multirow[t]{3}{*}{ Law } & Be well informed about acts, regulations, codes of practice, and guidance & 4.36 \\
\hline & Evaluate compliance with new legislation & 4.17 \\
\hline & $\begin{array}{l}\text { Advise managers, safety representatives, and employees of their legal obligations under health } \\
\text { and safety law }\end{array}$ & 4.10 \\
\hline \multirow[t]{5}{*}{ Hazards } & Assessing health problems, liaising with other doctors and nurses, and providing advice & 4.41 \\
\hline & Organising and monitoring programmes to check the health of people exposed to hazards at work & 4.19 \\
\hline & Assessing the work environment and evaluating risks & 4.11 \\
\hline & Providing advice and information on measures to control risks & 4.10 \\
\hline & Assessing and advising on first aid facilities & 3.66 \\
\hline \multirow[t]{7}{*}{ Fitness } & Assessing injury, disability, and handicap in relation to work & 4.46 \\
\hline & Assessing fitness for the job & 4.36 \\
\hline & Assessing and advising on early retirement due to ill health & 4.23 \\
\hline & Helping people to get back to work (rehabilitation) & 4.22 \\
\hline & Advising on drug and alcohol problems & 3.92 \\
\hline & Evaluating absence from work due to sickness & 3.84 \\
\hline & Advising on legal issues including the Disability Discrimination Act & 3.63 \\
\hline \multirow[t]{7}{*}{ Communication } & Reading, writing, and speaking clearly in English & 4.63 \\
\hline & Writing a report & 4.51 \\
\hline & Using language their audience can understand & 4.49 \\
\hline & Applying legal and other ethical requirements for confidentiality & 4.48 \\
\hline & Liaising with other professionals to organise and deliver training & 3.55 \\
\hline & Giving presentations to an audience using audiovisual equipment effectively & 3.30 \\
\hline & Working effectively as a member, secretary, or chair of a committee & 3.25 \\
\hline \multirow[t]{3}{*}{ Exposures } & Understanding and explaining the difference between work related and environment related disease & 4.11 \\
\hline & Assessing and advising on the control of environmental exposures from the workplace & 4.02 \\
\hline & Recognising and advising on hazards in the general environment & 3.82 \\
\hline \multirow[t]{9}{*}{ Research } & Use other professional experts when appropriate & 4.34 \\
\hline & Report on an investigation orally and in writing & 4.26 \\
\hline & Recognise and initiate the investigation of clusters of disease, e.g. cancer in a workforce & 4.10 \\
\hline & Be able to analyse and interpret data & 3.91 \\
\hline & Use a computer for the storage and analysis of data & 3.78 \\
\hline & Interpret scientific data in journals and from own research & 3.74 \\
\hline & Search published literature & 3.71 \\
\hline & Plan data collection for simple surveys & 3.54 \\
\hline & Convert a workplace health problem into a researchable question & 3.54 \\
\hline \multirow[t]{2}{*}{ Promotion } & Assessing needs for health promotion & 3.86 \\
\hline & Organising, providing, and evaluating work related health promotion activities & 3.66 \\
\hline \multirow[t]{13}{*}{ Management } & Identifying the occupational health needs of an organisation & 4.25 \\
\hline & Encouraging the use of occupational health services & 4.10 \\
\hline & Defining the goals and objectives of an occupational health service & 4.04 \\
\hline & Evaluating the quality of an occupational health service and carrying out clinical audit & 3.85 \\
\hline & Managing an occupational health department & 3.80 \\
\hline & Evaluating the service provided & 3.79 \\
\hline & Designing a training programme for occupational health staff & 3.66 \\
\hline & Organising record keeping using computers if appropriate & 3.65 \\
\hline & Defining the roles of occupational health staff and formulating job descriptions & 3.64 \\
\hline & Selecting, appointing, supervising, and appraising staff performance & 3.62 \\
\hline & Negotiating and managing a budget & 3.51 \\
\hline & Lead a team of multidisciplinary service providers & 3.43 \\
\hline & Plan the efficient use of multidisciplinary resources & 3.42 \\
\hline
\end{tabular}

areas. Respondents believed that the competencies outlined were very detailed and covered most of the aspects of occupational medicine they require. Very few new suggestions were made in the qualitative comments made by the participants in round 1 and round 2 . When analysed, the majority of the "new" issues raised were identified as already being part of the competencies described. One emerging theme was the need for clarity as to whom the OP represented: the employer or the employee. Comments were also made about the need for an increase in OPs to improve access to advice. The need for further training on the provision of advice related to the specific nature of their business and on stress related issues was also raised. It was suggested that OPs should work in closer collaboration with health and safety specialists and other members of a multidisciplinary team.

\section{DISCUSSION}

This is the first time that the views of employers, employees, and their representatives were sought to inform the training needs of OPs.
One of the problems faced in this study was participation. The research concentrated on the training of OPs, and participants understandably considered this to be a very specialised topic. Participants were offered descriptions of each training area and the competencies expected from OPs within those areas, but participation rates remained low. A higher response rate was observed in round 2. Qualitative comments and some of the descriptors used by round 1 participants were utilised to simplify the language in the questionnaire for the second round. The questionnaire used in round 2 was also significantly shorter than the one used in round 1 . Thus, the language used and the length of a questionnaire may influence participation. A low response rate when contacting enterprises on $\mathrm{OH}$ issues is not uncommon, ${ }^{9}$ but increasing the specificity of the target group can help to increase participation. ${ }^{8}$ In this study, we observed a $44 \%$ response rate with private EEF companies (compared to $16 \%$ for other private companies) as the regional offices for the EEF supported the study and its companies were requested to participate. Different response rates did not result in significant differences in the way in which the 


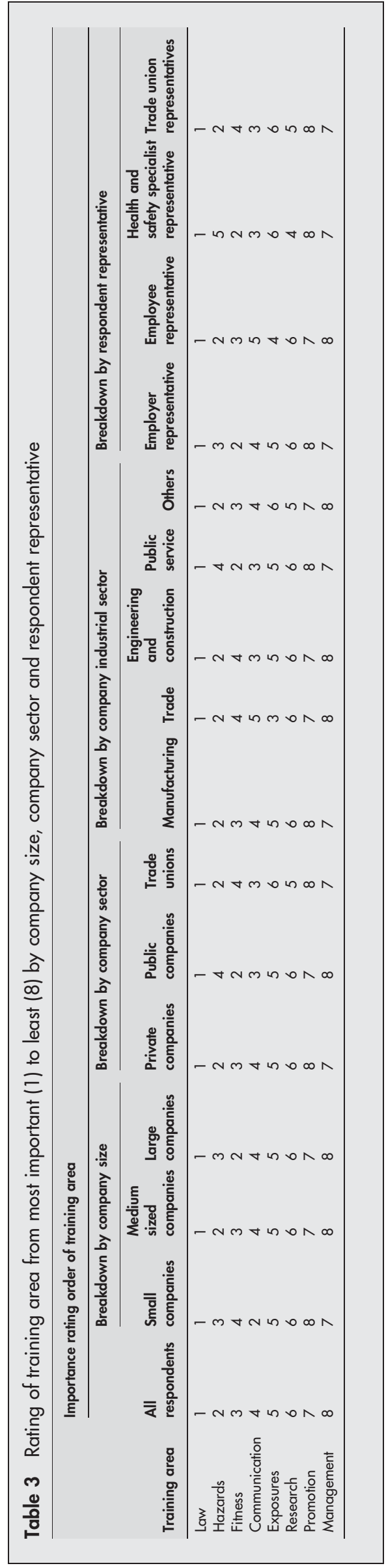

priorities for the training of OPs were rated for these two subgroups. This suggests that the low response rate did not jeopardise the generalisability of the results.

Our piloting of the use of CATI in ranking (round 2) established that it was difficult for the respondents to rank more than three items at a time. To investigate whether ranking differed in the second round, adjustments were made to the wording of the questions in round 2 to accommodate for qualitative comments made in the sub areas in round 1 . No significant differences were observed. Although the second round of the Delphi study helped to confirm the findings of the first round, because of the need to restrict ranking to three items, only limited interpretation of the results could be made, and round 2 did not identify any new concepts that could be used in further rounds. The use of CATI followed by email collation rounds may be a better alternative. ${ }^{17}$

This study shows that employers, employees, and their representatives considered all the established competencies important in the training of OPs and there was generally a reasonable concurrence among the subgroups analysed. This validates the training of OPs in the UK, which mirrors the EU competencies. ${ }^{6}$

The most highly rated area of competence was Law (law and ethics). The most important area of training within Law appears to be on "being well informed about acts, regulations, codes of practice, and guidance". Other studies of the $\mathrm{OH}$ needs among employers and employees did not consider the legal advisory aspects of $\mathrm{OH}$ service provision. ${ }^{89}$ In a previous Delphi study of OPs conducted by this research group, competency in Law was also highly rated (table 5). ${ }^{11}$ In this study respondents raised the issue of confusion regarding whether the OP represented the employer or the employee, and the ethical position of OPs needs to be better understood. In the workplace OPs tend to be "between medicine and management"19 and pure patient to doctor relationships can sometimes be blended with managerial issues. The importance of training of physicians to deal with such situations appears to be one area where the providers and customers of occupational medicine all seem to agree. ${ }^{1120}$ The Codes of Ethics for $\mathrm{OH}$ professionals which have been prepared by $\mathrm{ICOH}^{5}$ and the $\mathrm{FOM}^{21}$ need to be more widely disseminated to customers of OPs.

Training in the areas of Health Promotion and Management had the lowest scores, but $92 \%$ of respondents thought training in the area of Promotion was important while for Management, this was only 57\%. In other studies, these areas were not ranked as high priority by OPs and members of the SOM. ${ }^{1120}$ Customers commented that the OPs should be able to understand management principles so as to be able to inform management on the risks, but they do not believe that OPs should be part of management. There may be a lack of understanding of the purpose of training OPs in management skills. Many full time OPs have responsibility for managing staff and services.

Public sector organisations rated training in Fitness higher than private companies. This might be related to the fluidity in the job market in the private sector compared to the more permanent, or long term contracts in the public sector with its well established higher levels of sickness absence. ${ }^{22-25}$ There may be a greater need for OPs in the public sector to be involved with fitness and disability assessment and the provision of advice on rehabilitation and sickness absence reduction. Employees seem to have a more disease focused view of $\mathrm{OH}$ service provision than employers and seem very concerned about preventative methods. Their views were closer to those of OPs or SOM members. ${ }^{11} 20$ Similar observations were made in a recent Irish study on the 


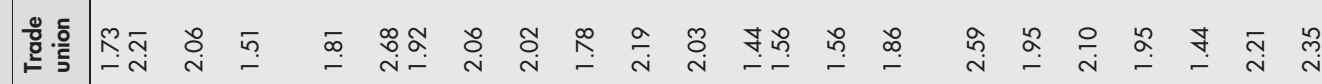

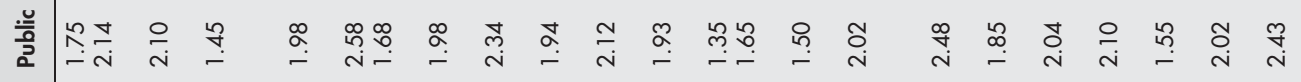

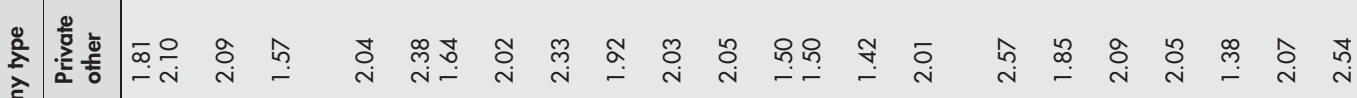
흘

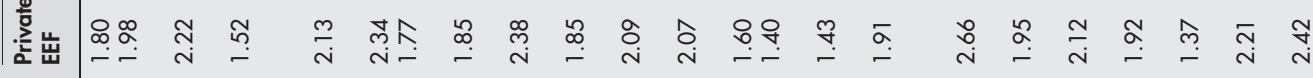

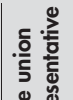

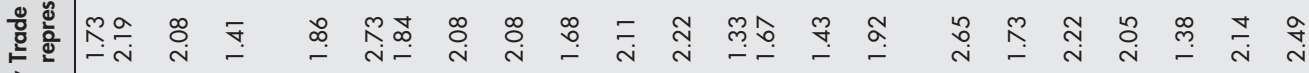

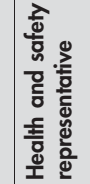

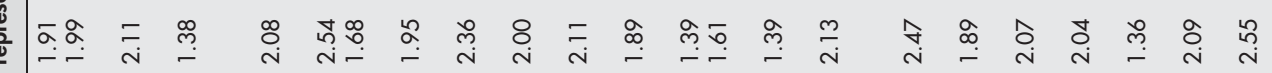

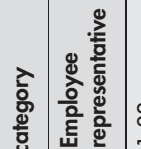

㠃

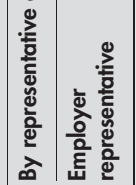

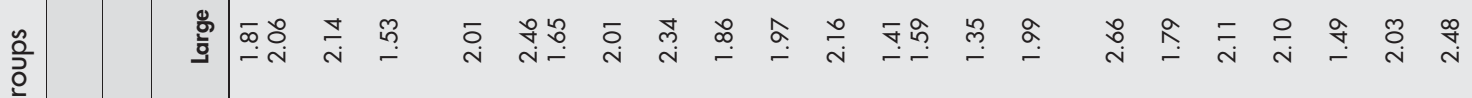
每

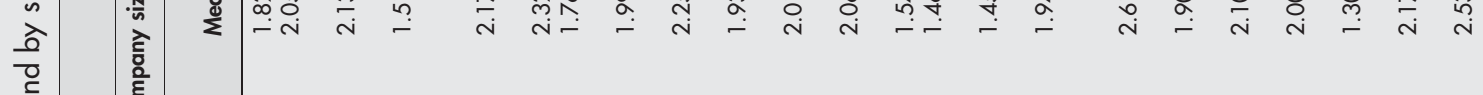

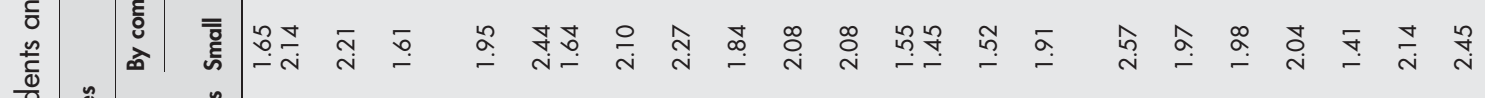

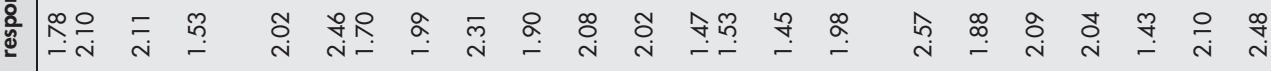

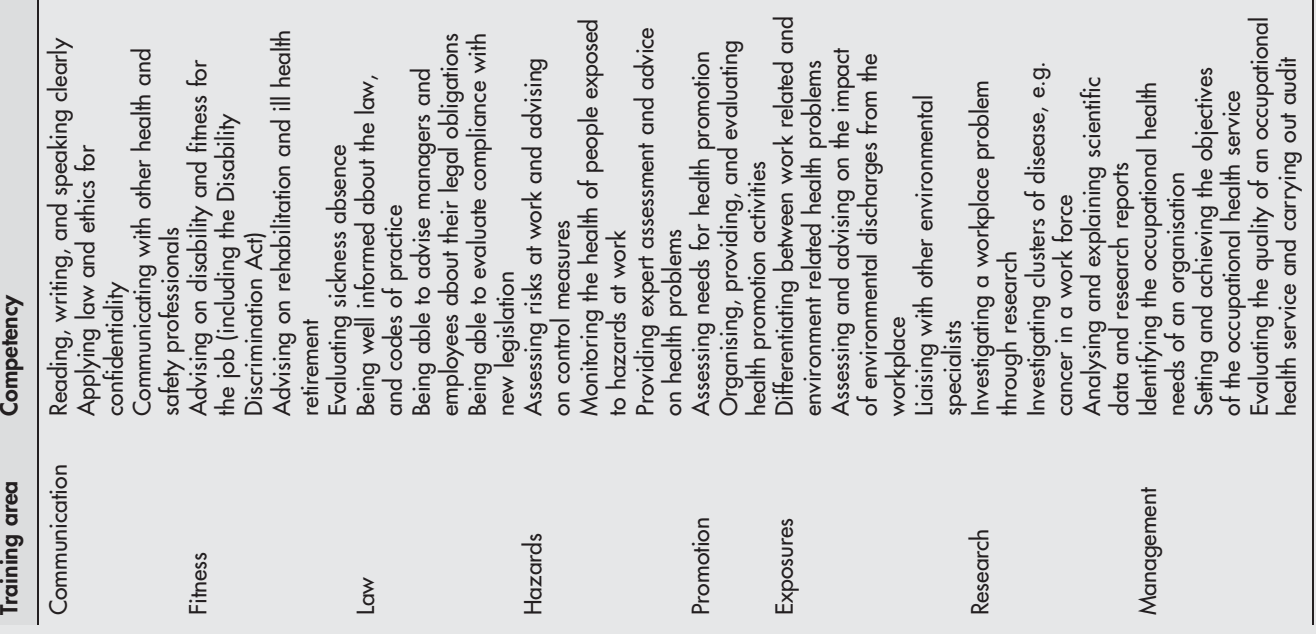


Table 5 Prioritisation of training areas by customers of occupational health (employers, employees, and their representatives) and occupational physicians

\begin{tabular}{lll}
\hline & \multicolumn{2}{l}{ Prioritisation by mean scores } \\
\cline { 2 - 3 } Competency & Customer group & $\begin{array}{l}\text { Occupational } \\
\text { physicians group" }\end{array}$ \\
\hline Law & 1 & 2 \\
Fitness & 2 & 5 \\
Hazards & 3 & 1 \\
Communications & 4 & 3 \\
Exposures & 5 & 8 \\
Research & 6 & 4 \\
Promotion & 7 & 7 \\
Management & 8 & 6 \\
\hline
\end{tabular}

comparison of employer and employee views on $\mathrm{OH}$ care needs. ${ }^{10}$

The area of Communication had the highest number of responses. Training in this area was also rated higher in importance by the trade union representatives than the employer representatives. It would appear that the concerns around this area are related to the content and clarity of medical reports and advice. All participants want clarity in their answers they get from OPs. The varying responsibilities of the physicians in the differing scenarios where they are called to provide advice are poorly understood and a recipe for discontent with the physician's subsequent advice and communication.

\section{Conclusion}

This study has established the priorities among employers and employee representatives of the competencies required of OPs. It has compared these with earlier studies of the priorities as determined by OPs. ${ }^{11}{ }^{20}$ All the established competency areas of OPs were regarded as important by their potential customers. However, there are substantial differences in the rating and ranking of the relative importance of these competencies between the physicians and their customers. Professional bodies responsible for the training of OPs need to strengthen training in the areas deemed important by the customers of Ops; for example, "advising on law and ethics", "identification and assessment of occupational hazards to health", "assessment of disability and fitness for work", and "communication". Given the evolution of occupational health there should be regular and systematic review of teaching curricula taking into account the views of the customers.

\section{ACKNOWLEDGEMENTS}

The authors acknowledge the invaluable assistance they have received from Ms. Kathleen Houston of SALUS Occupational Health and Safety; Mr Owen Tudor of the Trade Union Congress; Mr Ian Tasker of the Scottish Trade Union Congress; Dr Judith Brown, Mr Harper Gilmour, and Mr Keith Murray of the University of Glasgow. They also thank the Health and Safety Executive and the EEF-The Manufacturers' Organisation for funding the research and for their helpful feedbacks.

\section{Authors' affiliations}

K N Reetoo, E B Macdonald, Healthy Working Lives Research Group, Public Health and Health Policy Section, Division of Community based Sciences, University of Glasgow, UK

J M Harrington, Emeritus Professor of Occupational Health, The

University of Birmingham, UK

Competing interests: none declared

\section{REFERENCES}

1 WHO. Global strategy on occupational health for all. Recommendation of the Second Meeting of the WHO Collaborating Centres in Occupational Health. Geneva: World Health Organisation, 1995.

2 Royal College of Physicians. Occupational medicine training record. London: Faculty of Occupational Medicine of the Royal College of Physicians, 1995.

3 ILO. Convention 161 concerning occupational health services. Geneva: International Labour Organisation, 1985.

4 ILO. Recommendation 171 concerning occupational health services. Geneva: International Labour Organisation, 1985.

$5 \mathrm{ICOH}$. International code of ethics for occupational health professionals. Italy: International Commission of Occupational Health, 2002.

6 University of Glasgow. Competencies of occupational physicians: requirements of occupational medicine training in Europe proceedings. Glasgow: University of Glasgow, 1997.

7 Macdonald EB. Audit and quality in occupational health. Occup Med 1992;42:7-1 1

8 Williams N, Sobti A, Aw TC. Comparison of perceived occupational health needs among managers, employee representatives and occupational physicians. Occup Med 1994;44:205-8

9 Bradshaw LM, Curran AD, Eskin F, et al. Provision and perception of occupational health in small and medium-sized enterprises in Sheffield, UK. Occup Med 2001;51:39-44.

10 Reid A, Malone J. A cross-sectional study of employer and employee occupational health needs and priorities within the Irish Civil Service. Occup Med 2003;53:41-5.

11 Macdonald EB, Ritchie KA, Murray KJ, et al. Requirements for occupational medicine training in Europe-a Delphi study. Occup Environ Med 2000;57:98-105.

12 Lindstone HA, Turoff M. The Delphi method: techniques and applications. Reading, MA: Addison-Wesley Publishing Company, 1975.

13 Moscovice I, Armstrong P, Shortell S, et al. Health services research for decision-makers: the use of the Delphi technique to determine health priorities. Journal of Health Politics, Policy \& Law 1977;2:388-410.

14 Harrington JM. Research priorities in occupational medicine: a survey of United Kingdom medical opinion by the Delphi technique. Occup Med 1994;51:289-94.

15 Harrington JM, Calvert IA. Research priorities in occupation medicine: a survey of United Kingdom personnel managers. Occup Med 1996;53:642-4.

16 Van der Beek AJ, Frings-Dresen MHW, van Dijk FJH, et al. Priorities in occupational health research: a Delphi study in The Netherlands. Occup Environ Med 1997;54:504-10

17 Beaumont DG. The interaction between general practitioners and occupational health professionals in relation to rehabilitation for work: a Delphi study. Occup Med 2003;53:249-53.

18 Standard industrial classification of economic activities. London: HMSO, 1992.

19 Walsh DC. Corporate physicians: between medicine and management. New Haven, CT: Yale University Press, 1987.

20 Turner S, Hobson J, D'Auria D, et al. Continuing professional development of occupational medicine practitioners: a needs assessment. Occup Med (Oxf) 2004;54:14-20.

21 Royal College of Physicians. Guidance on ethics for occupational physicians, 5th edn. London: Faculty of Occupational Medicine of the Royal College of Physicians, 1999.

22 Counting the costs: absence and labour turnover survey report. London: CBI Publications, 2002.

23 Working well together: managing attendance in the public sector. London: Cabinet Office, 1998.

24 Analysis of sickness absence in the Public Sector. London: Cabinet Office, 2002.

25 Merrick N. Sickness strikes more often in the civil service. People Management 1995; 1(18): 10-12. 